\title{
PENCAHAYAAN DAN RUANG GERAK EFEKTIF SEBAGAI INDIKATOR KENYAMANAN PADA RUMAH SEDERHANA SEHAT YANG ERGONOMIS
}

(Studi Kasus Rumah Sederhana Sehat di Bekasi)

\author{
Ashadi $^{1}$, Nelfiyanti $^{2}$, Anisa $^{3}$ \\ 1 Jurusan Arsitektur, Fakultas Teknik, Universitas Muhammadiyah Jakarta \\ ${ }^{2}$ Jurusan Teknik Industri, Fakultas Teknik, Universitas Muhammadiyah Jakarta \\ ${ }^{3}$ Jurusan Arsitektur, Fakultas Teknik, Universitas Muhammadiyah Jakarta \\ Jl. Cempaka Putih Tengah 27 Jakarta Pusat 10510 \\ ashadihadiwinoto@yahoo.co.id, nelfiyanthi@gmail.com, sasa909691@yahoo.com
}

\begin{abstract}
ABSTRAK. Penelitian ini dilatarbelakangi tentang pentingnya pencahayaan dan ruang gerak untuk mewujudkan kenyamanan pada rumah sederhana yang ergonomis. Studi kasus yang diambil adalah Rumah Sederhana Sehat yang ada di Bekasi. Tujuannya adalah untuk mendeskripsikan kenyamanan penghuni pada rumah dilihat dari pencahayaan dan ruang gerak yang tersedia. Metode yang digunakan adalah metode deskriptif kualitatif dengan mengambil kasus secara purposif sampling. Hasil yang didapatkan dari penelitian ini adalah dengan adanya bukaan yang cukup, cahaya dapat masuk secara merata ke dalam ruangan, perkecualian pada kamar mandi yang terletak di tengah. Dengan adanya cahaya masuk secara merata, maka semua ruangan bisa digunakan untuk beraktivitas. Hal ini membuat semua ruangan di dalam rumah menjadi nyaman. Ukuran bukaan yang terdapat pada rumah sederhana yang diteliti mempunyai ukuran sesuai dengan standar sehingga matahari dapat masuk untuk menerangi ruangan. RSS di Bekasi juga memiliki ruang gerak efektif yang cukup. Rata-rata prosentase ruang gerak pada rumah adalah $79,35 \%$ yang tergolong cukup luas untuk beraktivitas.
\end{abstract}

Kata kunci: kenyamanan, pencahayaan, ruang gerak, rumah sederhana yang ergonomis

ABSTRACT. This research has been motivated on the significancy of lighting and space in order to create comfort within ergonomic low income house. There are some case studies of Rumah Sederhana Sehat have been conducted within Bekasi area. The aim of this research is to describe the comfort of the dwellers from the aspect of lighting and existing space. The method that has been used is a qualitative descriptive method by taking case studies with sampling purposive method. The result of this research will provide some standard with sufficient windows, prevalent lighting within room, except for bathroom which located in the middle of house. With a prevalent lighting within room, therefore all the room relatively could be used for activities. This condition will create a comfort space within a house. The dimension of windows within case studies have a dimension as a minimum standard requirement which make sunlight could enter all the room. RSS within Bekasi also have a sufficient efective space, which is about $79,35 \%$ of house area, and this is regarded as a sufficient space to do activity within a house.

Kata kunci: kenyamanan, pencahayaan, ruang gerak, rumah sederhana yang ergonomis

\section{PENDAHULUAN}

Kenyamanan dalam ruang merupakan tolak ukur yang penting dalam desain rumah sederhana yang ergonomis. Keberhasilan suatu aktivitas di dalam ruang salah satunya dipengaruhi oleh kenyamanan. Indikator yang digunakan untuk mengukur kenyamanan antara lain adalah pencahayaan dan ruang gerak yang tersedia dalam rumah. Menurut Pedoman Umum Rumah Sederhana Sehat tahun 2002 [1], rumah sebagai tempat tinggal yang memenuhi syarat kesehatan dan kenyamanan dipengaruhi oleh 3 aspek yaitu pencahayaan, penghawaan serta suhu udara dan kelembaban dalam ruangan. Aspek-aspek tersebut merupakan dasar atau kaidah perencanaan rumah sehat dan nyaman.

Kenyamanan dapat dicapai salah satunya dengan pencahayaan alami. Kenyamanan tersebut meliputi kenyamanan visual dan kenyamanan termal. Kenyamanan visual berkaitan dengan cahaya alami yang membantu manusia untuk menggunakan penglihatannya. Pencahayaan yang sesuai dengan kebutuhan dan kegiatan yang sedang dilakukan akan memberikan kenyamanan visual. Sedangkan kenyamanan termal berkaitan dengan cahaya matahari yang memberikan energi panas ke dalam ruangan. [2] 
Ergonomi adalah ilmu yang mempelajari berbagai aspek dan karakteristik manusia (kemampuan, kelebihan, keterbatasan dan lain-lain) yang relevan dalam konteks kerja, serta memanfaatkan informasi yang diperoleh dalam upaya merancang produk, mesin, alat, lingkungan serta sistem kerja yang terbaik. Tujuan utama yang hendak dicapai adalah tercapainya sistem kerja yang produktif dan kualitas kerja terbaik, disertai dengan kemudahan, kenyamanan dan efisiensi kerja, tanpa mengabaikan kesehatan dan keselamatan kerja. Dalam perkembangannya, kata kerja dapat dikonotasikan sebagai semua tempat dimana manusia melakukan berbagai aktivitas untuk mencapai tujuannya. [3]

Ada 4 tolok ukur ergonomi yaitu:

(1) Anthropometri yaitu berhubungan dengan pengukuran dimensi tubuh manusia;

(2) Kinetik yaitu berhubungan dengan otot dan gerakan kerja (aktivitas) manusia;

(3) Fisiologi yaitu berhubungan dnegan kebutuhan fisik dari manusia (kebutuhan ruang gerak);

(4) Psikologi yaitu berhubungan dengan aspek mental manusia (kebutuhan akan rasa aman)

Rumah Sederhana Sehat diambil sebagai kasus penelitian dengan pertimbangan bahwa desain rumah sederhana juga harus memenuhi syarat ergonomi sehingga penghuninya dapat beraktivitas secara produktif dengan kualitas terbaik. Penelitian ini difokuskan pada pencahayaan dan ruang gerak efektif sebagai indikator kenyamanan pada rumah sederhana sehat yang ergonomis dengan kasus rumah sederhana sehat di Kota Bekasi.

\section{PENCAHAYAAN}

Desain Bukaan untuk Memasukkan Cahaya

Ada 3 cara yang dapat digunakan untuk mendesain bukaan untuk cahaya yaitu:

(1) Tempatkan bukaan sesuai fungsi ruang;

(2) Jangan berlebihan dalam hal ukuran;

(3) Refleksi atau pantulan dari permukaan bidang.

1. Tempatkan Bukaan Sesuai Fungsi Ruang Ada dua hal yang kita dapatkan dari matahari yaitu cahaya dan panas. Cahaya bisa dipakai untuk pengganti lampu penerangan khususnya siang hari. Untuk daerah iklim tropis, panas akibat radiasi matahari sedapat mungkin dikendalikan agar tidak merusak atau menimbulkan ketidaknyamanan. Berikut adalah daftar beberapa ruang dengan cahaya yang dibutuhkan. Tempatkan ventilasi yang sesuai dengan fungsi setiap ruang dan manfaatkan cahayanya untuk mendukung aktivitas di dalam ruang tersebut. Cahaya yang masuk ke dalam ruang dapat diatur sedemikian rupa dengan memperhatikan arah hadap/ orientasi bukaan (jendela). Angka radiasi setiap orientasi memiliki besar yang berbeda (lihat tabel radiasi). Sebaiknya, selain itu tinggi perletakan dan bentuk bukaan perlu diperhatikan agar sudut cahaya matahari yang tajam di pagi atau sore hari tidak mengganggu. [4]. Dalam mendesain bukaan untuk memasukkan cahaya harus disesuaikan dengan fungsi ruang yang ada di dalamnya. Karena setiap ruang dengan aktivitas tertentu membutuhkan cahaya yang berbeda-beda.

Tabel 1. Jenis Ruang dan Pencahayaan

\begin{tabular}{|c|c|c|}
\hline Jenis ruang & Jenis pencahayaan yang sesuai & $\begin{array}{l}\text { Letak bukaan yang } \\
\text { disarankan }\end{array}$ \\
\hline Ruang Tidur & Pencahayaan pagi (matahari pagi) & Tenggara sampai timur laut \\
\hline Gudang, kamar mandi & $\begin{array}{l}\text { Matahari sore (paling tinggi tingkat } \\
\text { radiasinya) agar tak lembab dan jamur } \\
\text { terbunuh }\end{array}$ & Barat atau timur \\
\hline $\begin{array}{l}\text { Ruang keluarga, ruang } \\
\text { makan, ruang tamu }\end{array}$ & $\begin{array}{l}\text { Tingkat aktivitas tinggi, perlu cahaya } \\
\text { hangat }\end{array}$ & $\begin{array}{l}\text { Barat laut atau barat daya } \\
\text { atau utara dan selatan }\end{array}$ \\
\hline $\begin{array}{l}\text { Dapur, ruang kerja } \\
\text { (komputer) }\end{array}$ & $\begin{array}{l}\text { Butuh cahaya yang adem agar panas } \\
\text { yang masuk tidak menaikkan suhu ruang }\end{array}$ & Utara dan selatan \\
\hline
\end{tabular}

\section{Jangan berlebihan}

Bukaan untuk memasukkan cahaya harus disesuaikan dengan kebutuhan. Berlebihan dalam memasukkan cahaya justru akan menimbulkan efek negatif. Menurut data SNI, banyaknya lubang cahaya ideal dalam suatu 
ruang dinyatakan oleh nilai WWR (Wall Window Ratio). WWR adalah perbandingan luas jendela dengan luas seluruh dinding luar pada orientasi yang ditentukan. Dari ketentuan ini nilai idealnya adalah $20 \%$ dari luas dinding keseluruhan. Contoh perhitungan ukuran ruang $4 \mathrm{~m} \times 4 \mathrm{~m}=16 \mathrm{~m}^{2}$. Maka luas bukaan cahaya ideal adalah $20 \% \times 16 \mathrm{~m}^{2}=3,2 \mathrm{~m}^{2}$. Luas itu bisa dipenuhi dengan jendela ukuran $1 \mathrm{~m} \times 1,6 \mathrm{~m}$ (dua buah) atau jendela ukuran $2 \mathrm{~m} \times 1,6 \mathrm{~m}$ (satu buah).[4]

3. Refleksi atau pantulan dari permukaan bidang

Merancang bukaan untuk cahaya juga perlu memperhatikan warna dan detail permukaan bidang yang terkena sinar. Warna cerah lebih banyak memantulkan sinar daripada warna gelap. Warna putih akan memantulkan $70 \%$ $80 \%$ sinar matahari; warna muda (biru muda, kuning muda, hijau muda, coklat muda) $20 \%$ $60 \%$; warna gelap (hitam, coklat, abu-abu tua) memantulkan <20\% (Sumber : SNI 03-61972000). Agar terlihat terang dan mengurangi panas, terapkan warna-warna muda.

\section{Pengaruh cahaya pada kesehatan manusia [5]}

Dalam perancangan bangunan, peletakan lubang jendela perlu diusahakan agar pada sisi utara dan selatan bangunan lebih banyak. Sedangkan perletakan jendela pada sisi timur dan barat bangunan sebaiknya dihindari. Terutama pada sisi barat bangunan timbul masalah karena cahaya matahari dari barat cukup panas dan menyengat. Salah satu pengaruh cahaya alam pada bangunan adalah suhu dari intensitas sinar matahari yang langsung dapat meningkatkan suhu dinding akibat konduksi dan suhu ruangan bila sinar matahari langsung masuk pada ruangan.

Tanggapan manusia terhadap cahaya rupanya berbeda-beda dalam masing-masing kebudayaan. Untuk kebanyakan manusia, cahaya merah berarti hangat, sedangkan cahaya biru mengakibatkan perasaan dingin. Karena pencahayaan matahari di daerah tropis mengandung gejala samping dengan sinar panas, maka di daerah tersebut manusia sering menganggap ruang yang agak gelap sebagai sejuk dan nyaman. Akan tetapi untuk melakukan kegiatan tertentu diadakan standar penyinaran alamiah maupun penerangan buatan terutama untuk ruang kerja. Walaupun demikian daya produksi meningkat jika pencahayaan berubah-ubah mengikuti perputaran waktu sehari. Penerangan buatan yang makin jauh dari jendela seolah-olah menggantikan kurangnya cahaya alam. Karena pencahayaan buatan dengan lampu dan sebagainya mempengaruhi kesehatan manusia, maka dibutuhkan pencahayaan alam yang terang, bebas kesilauan dan tanpa sinar panas. Untuk memenuhi tuntutan berlawanan ini, maka sebaiknya sinar matahari tidak diterima secara langsung melainkan sinar tersebut dicerminkan/ dipantulkan misalnya dalam air kolam (menghilangkan panasnya)

\section{Ergonomi}

Ergonomi yaitu ilmu yang mempelajari perilaku manusia dalam kaitannya dengan pekerjaan mereka. Sasaran penelitian ergonomi ialah manusia pada saat bekerja dalam lingkungan. Secara singkat dapat dikatakan bahwa ergonomi ialah penyesuaian tugas pekerjaan dengan kondisi tubuh manusia ialah untuk menurunkan stress yang akan dihadapi. Upayanya antara lain berupa menyesuaikan ukuran tempat kerja dengan dimensi tubuh agar tidak melelahkan, pengaturan suhu, cahaya dan kelembaban bertujuan agar sesuai dengan kebutuhan tubuh manusia. http://www.depkes.go.id/downloads/Ergonomi. PDF) [6]

Ergonomi adalah ilmu yang menemukan dan mengumpulkan informasi tentang tingkah laku, kemampuan, keterbatasan dan karakteristik manusia untuk perancangan mesin, peralatan, sistem kerja dan lingkungan yang produktif, aman nyaman dan efektif bagi manusia. Ergonomi merupakan suatu cabang ilmu yang sistematis untuk memanfaatkan informasi mengenai sifat manusia, kemampuan manusia dan keterbatasannya untuk merancang suatu sistem kerja yang baik agar tujuan dapat dicapai dengan efektif, aman dan nyaman. (Sutalaksana dalam Purwantiasning [7].

Penyelidikan ergonomi dibedakan menjadi empat kelompok, yakni:

i. Penyelidikan tentang tampilan/ display. Penyelidikan pada suatu perangkat yang menyajikan informasi tentang lingkungan dan mengkomunikasikannya pada manusia antara lain dalam bentuk tandatanda, angka dan lambang.

ii. Penyelidikan tentang kekuatan fisik manusia. Penyelidikan dengan mengukur kekuatan serta ketahanan fisik manusia pada saat kerja,termasuk perancangan obyek serta peralatan yang sesuai dengan kemampuan fisik manusia beraktivitas.

iii. Penyelidikan tentang ukuran tempat kerja. Penyelidikan ini bertujuan untuk mendapatkan rancangan tempat kerja 
yang sesuai dengan ukuran atau dimensi tubuh manusia.

iv. Penyelidikan tentang lingkungan kerja. Meliputi penyelidikan mengenai kondisi lingkungan fisik tempat kerja dan fasilitas kerja, misalnya pengaturan cahaya, kebisingan, temperatur dan suara. [7]

\section{METODOLOGI PENELITIAN}

Penelitian ini menggunakan metode deskriptif kualitatif dalam pengambilan data dan analisa, dengan mengamati dan melakukan analisa terhadap kenyamanan berdasarkan pencahayaan dan ruang gerak di dalam rumah. Metode deskriptif bertujuan untuk mendapatkan gambaran atau deskripsi tentang suatu permasalahan yang akan diselesaikan. Pengertian deskriptif berdasarkan Kamus besar Bahasa Indonesia adalah suatu bentuk penelitian yang ditujukan untuk mendeskripsikan fenomena-fenomena yang ada, baik fenomena alamiah maupun fenomena buatan manusia. Fenomena itu bisa berupa bentuk, aktivitas, karakteristik, perubahan, hubungan, kesamaan dan perbedaan antara fenomena yang satu dengan fenomena lainnya. Bogdan dan Taylor dalam Moleong menyatakan bahwa metodologi kualitatif sebagai prosedur penelitian yang menghasilkan data deskriptif berupa kata-kata tertulis atau lisan dari orang-orang dan perilaku yang dapat diamati. [8]

Kota Bekasi dijadikan lokasi penelitian karena perkembangan pembangunan rumah sederhana yang sangat pesat. Lingkup materi penelitian meliputi materi fisik dan nonfisik. Materi fisik didapatkan berdasarkan pengamatan dan pengukuran. Sedangkan materi non fisik didapatkan dari hasil wawancara untuk mendapatkan kenyamanan secara kualitatif. Obyek penelitian adalah rumah sederhana dengan luasan $\leq 36 \mathrm{~m}^{2}$ sesuai dengan Pedoman Umum Rumah Sederhana Sehat bahwa kebutuhan luas minimum bangunan untuk Rumah sederhana untuk 4 jiwa adalah $36 \mathrm{~m}^{2}$. Metode pengambilan obyek sebagai sampel penelitian adalah purposive sampling , yaitu pengambilan sampel dengan tujuan tertentu. Selanjutnya sampel dalam penelitian ini disebut sebagai kasus.

\section{HASIL DAN PEMBAHASAN}

\section{Hasil Pengamatan Lapangan}

Rumah yang dijadikan kasus penelitian berjumlah 4 dengan rincian sebagai berikut : (1) Rumah terletak di hook dan masih dalam bentuk asli;

(2) Rumah terletak di hook dan sudah mengalami perubahan;

(3) Rumah terletak di tengah dan masih dalam bentuk asli;

(4) Rumah terletak di tengah dan sudah mengalami perubahan (tabel 1)

\section{Pencahayaan Sebagai Indikator Rumah Sederhana Yang Ergonomis}

Pencahayaan digunakan sebagai salah satu indikator rumah sederhana yang ergonomis dengan pertimbangan bahwa kenyamanan beraktivitas dalam ruang dipengaruhi oleh cahaya yang masuk ke dalam ruangan. Tidak semua ruangan membutuhkan cahaya yang sama banyak. Karena kebutuhan cahaya tergantung dari aktivitas yang dilakukan di dalam ruang. Karena itulah dengan melakukan observasi didapatkan data jangkauan cahaya yang dilengkapi dengan wawancara untuk mendapatkan data kenyamanan ruang.

Kebutuhan pencahayaan selain dipengaruhi oleh aktivitas yang dilakukan di dalam ruangan juga dipengaruhi oleh usia pengguna. Dapat dilihat pada literatur [4] dinyatakan bahwa kebutuhan cahaya setiap orang berbeda-beda tergantung pada: (1) usia; (2) ukuran obyek yang terlihat; dan (3) tingkat ketelitian/kesulitan pekerjaan yang dilakukan. Dijelaskan juga bahwa orang yang berumur 60 tahun membutuhkan 15x lebih tinggi tingkat cahaya dibanding anak umur 10 tahun. Jadi walaupun aktivitas yang dilakukan sama tetapi kalau manusia sebagai pelaku kegiatannya berbeda, tingkat pencahayaan yang dibutuhkan juga berbeda.

Pengamatan tentang jangkauan cahaya pada masing-masing kasus dilakukan 3 kali dalam 1 hari. Dengan jumlah kasus sebanyak 4 rumah maka total dilakukan pengamatan selama 12 kali. Pengamatan dilakukan saat cuaca cerah. Pengamatan tersebut dilakukan pagi hari (08.00), siang (12.00) dan sore (16.00). Pengamatan tentang pencahayaan dilakukan selama 3 kali untuk mendapatkan hasil yang akurat. Disamping itu pembatasan waktu dari jam 08.00 sampai 16.00 berdasarkan Pedoman Umum Rumah Sederhana sehat 
bahwa cahaya efektif dapat diperoleh dari jam 08.00 sampai 16.00 .

Dari pengamatan yang dilakukan, didapatkan bahwa pada desain asli semua ruang mendapatkan cahaya matahari yang cukup untuk beraktivitas. Perkecualian pada kamar mandi kasus rumah yang terletak di tengah, tidak mendapatkan cahaya yang cukup untuk beraktivitas. Hal ini terjadi karena posisi kamar mandi biasanya diapit dengan ruangan yang lain. Pada kasus yang sudah mengalami perubahan, ada ruangan yang tidak maksimal mendapatkan cahaya matahari karena terhalang oleh ruang lain. Ruang-ruang yang dimaksud misalnya ruang serbaguna. Perluasan untuk ruang-ruang tersebut adalah ke arah belakang sehingga tidak mendapatkan cahaya dari depan maupun samping.

Tabel 2. Hasil Pengamatan Lapangan
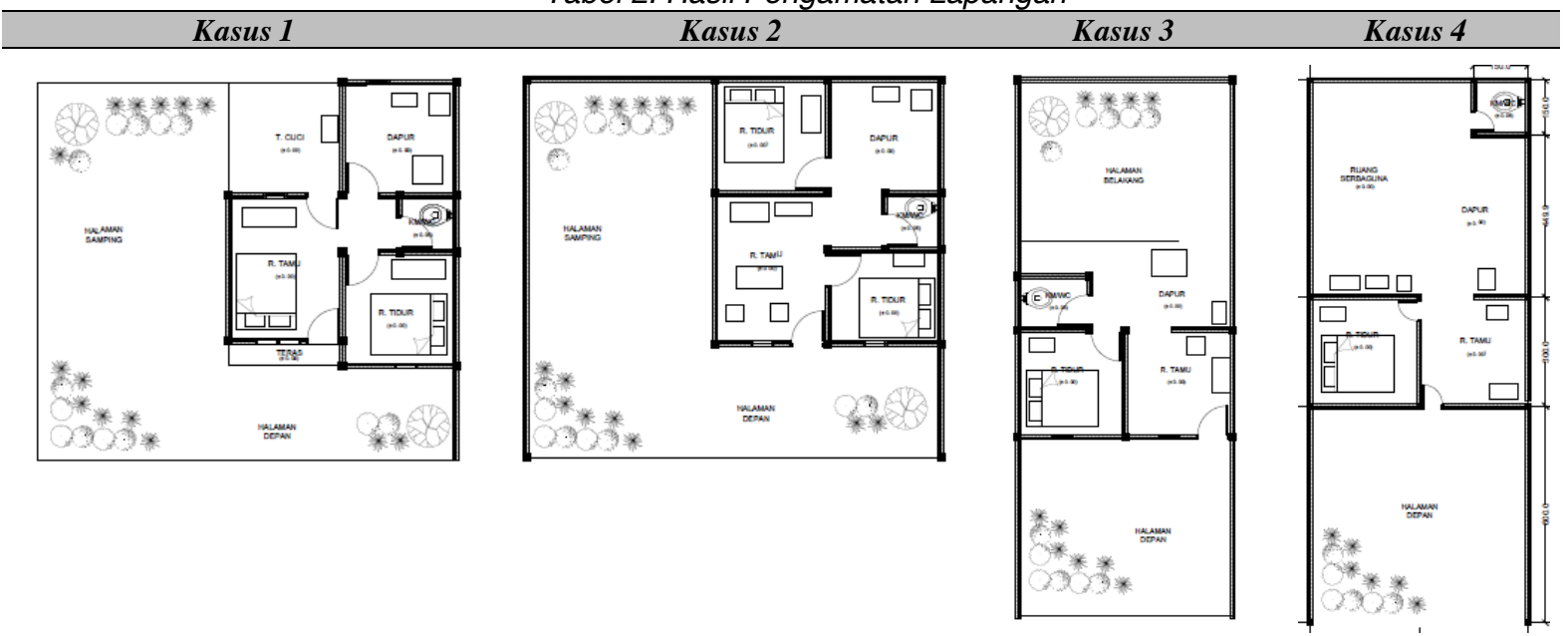

\begin{tabular}{cccc}
\hline Rumah menghadap selatan & Rumah menghadap timur & $\begin{array}{c}\text { Rumah } \\
\text { menghadap timur }\end{array}$ & $\begin{array}{c}\text { Rumah } \\
\text { menghadap utara }\end{array}$ \\
\hline Hook - asli & Hook - berubah & Tengah - asli & $\begin{array}{c}\text { Tengah - } \\
\text { berubah }\end{array}$ \\
\hline $36 / 110 \mathrm{~m}^{2}$ & $110 \mathrm{~m}^{2}$ & $21 / 90 \mathrm{~m}^{2}$ & $90 \mathrm{~m}^{2}$ \\
\hline & & & \\
\hline
\end{tabular}

Tabel 3. Jangkauan cahaya pada RSS di Bekasi

\begin{tabular}{|c|c|c|c|c|c|c|c|c|c|c|c|c|}
\hline \multirow[t]{2}{*}{ Ruang } & \multicolumn{4}{|c|}{ Pagi (08.00) } & \multicolumn{4}{|c|}{ Siang (12.00) } & \multicolumn{4}{|c|}{ Sore $(16.00)$} \\
\hline & K1 & $\mathrm{K} 2$ & K3 & K4 & K1 & $\mathrm{K} 2$ & K3 & K4 & K1 & $\mathrm{K} 2$ & K3 & K4 \\
\hline Ruang Tamu & $\sqrt{ } \sqrt{ }$ & $\sqrt{ } \sqrt{ }$ & $\sqrt{ } \sqrt{ }$ & $\sqrt{ } \sqrt{ }$ & $\sqrt{ } \sqrt{ }$ & $\sqrt{ } \sqrt{ }$ & $\sqrt{ }$ & $\sqrt{ } \sqrt{ }$ & $\sqrt{ } \sqrt{ }$ & $\sqrt{ } \sqrt{ }$ & $\sqrt{ }$ & $\sqrt{ } \sqrt{ }$ \\
\hline Kamar tidur 1 & $\sqrt{ } \sqrt{ }$ & $\sqrt{ } \sqrt{ }$ & $\sqrt{ } \sqrt{ }$ & $\sqrt{ } \sqrt{ }$ & $\sqrt{ } \sqrt{ }$ & $\sqrt{ } \sqrt{ }$ & $\sqrt{ } \sqrt{ }$ & $\sqrt{ } \sqrt{ }$ & $\sqrt{ } \sqrt{ }$ & $\sqrt{ } \sqrt{ }$ & $\sqrt{ } \sqrt{ }$ & $\sqrt{ } \sqrt{ }$ \\
\hline Kamar tidur 2 & & $\sqrt{ } \sqrt{ }$ & & & & $\sqrt{ } \sqrt{ }$ & & & & $\sqrt{ } \sqrt{ }$ & & \\
\hline Dapur & $\sqrt{ } \sqrt{ }$ & $\sqrt{ }$ & & $\sqrt{ } \sqrt{ }$ & $\sqrt{ } \sqrt{ }$ & $\sqrt{ }$ & & $\sqrt{ } \sqrt{ }$ & $\sqrt{ } \sqrt{ }$ & $\sqrt{ }$ & & $\sqrt{ } \sqrt{ }$ \\
\hline Kamar Mandi & - & - & $\sqrt{ }$ & - & - & - & $\sqrt{ }$ & - & - & - & $\sqrt{ }$ & - \\
\hline Ruang serbaguna & & & & $\sqrt{ }$ & & & & $\sqrt{ }$ & & & & $\sqrt{ }$ \\
\hline
\end{tabular}

Keterangan :

$\sqrt{ } \sqrt{ }$ Seluruh ruangan

$\sqrt{ }$ Sebagian (1-1,5 meter)/ remang-remang

- Gelap 
Setelah melakukan pengamatan terhadap jangkauan pencahayaan pada RSS di Bekasi, langkah berikutnya adalah melakukan pengukuran terhadap bukaan yang digunakan untuk memasukkan cahaya. Umumnya dalam desain RSS, bukaan untuk memasukkan cahaya adalah sama dengan bukaan untuk memasukkan udara.
Hasil pengukuran tersebut dapat dilihat pada tabel 5 di bawah. Prosentase rata-rata bukaan untuk memasukkan cahaya terhadap luas ruang pada RSS di Bekasi adalah 16,18\%. Prosentase bukaan pada ruang yang ada pada RSS di Kota Bekasi berkisar antara 4,57\%$38,67 \%$. Bukaan terkecil pada kamar mandi dan bukaan terbesar pada dapur.

Tabel 5. Luas Ruang, Luas bukaan dan Prosentase Bukaan pada RSS di Bekasi

\begin{tabular}{|c|c|c|c|c|c|c|c|c|c|c|c|c|c|}
\hline & \multicolumn{3}{|c|}{ K1 } & \multicolumn{3}{|c|}{$\mathrm{K} 2$} & \multicolumn{3}{|c|}{$\mathrm{K} 3$} & \multicolumn{3}{|c|}{$\mathrm{K} 4$} & \multirow[b]{2}{*}{ 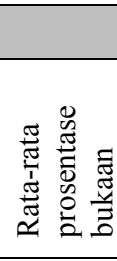 } \\
\hline $\begin{array}{l}\text { Nama } \\
\text { Ruang }\end{array}$ & 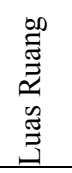 & 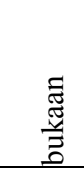 & $\%$ & 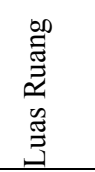 & 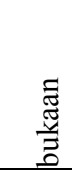 & $\%$ & 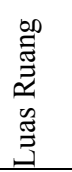 & 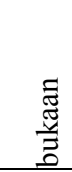 & $\%$ & 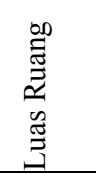 & 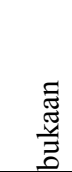 & $\%$ & \\
\hline \multirow{7}{*}{$\begin{array}{l}\text { ruang tamu } \\
\text { kamar } 1 \\
\text { kamar } 2 \\
\text { Dapur } \\
\text { kamar } \\
\text { mandi } \\
\text { ruang } \\
\text { serbaguna }\end{array}$} & 13,5 & 3,78 & 28,00 & \multirow{6}{*}{$\begin{array}{r}12 \\
7,5 \\
9 \\
9\end{array}$} & \multirow{4}{*}{$\begin{array}{r}2,52 \\
1,8 \\
1,8 \\
3,48\end{array}$} & \multirow{3}{*}{$\begin{array}{l}21,00 \\
24,00 \\
20,00\end{array}$} & 9 & 1,28 & 14,22 & 9 & 1,20 & 13,33 & 19,14 \\
\hline & 9 & 1,8 & 20,00 & & & & 9 & 1,28 & 14,22 & 9 & 1,20 & 13,33 & 17,89 \\
\hline & & & & & & & & & & & & & 20,00 \\
\hline & 9 & 1,8 & 20,00 & & & 38,67 & & & & 16,5 & 1,20 & 7,27 & 21,98 \\
\hline & 2,25 & & & & & & 2,25 & & & 2,25 & & & \\
\hline & & & & & & & & & & 21 & 0,96 & 4,57 & 4,57 \\
\hline & 36 & 7,38 & 20,50 & 39,75 & 9,6 & 24,15 & 21 & 2,56 & 12,19 & 57,75 & 4,56 & 7,90 & 16,18 \\
\hline
\end{tabular}

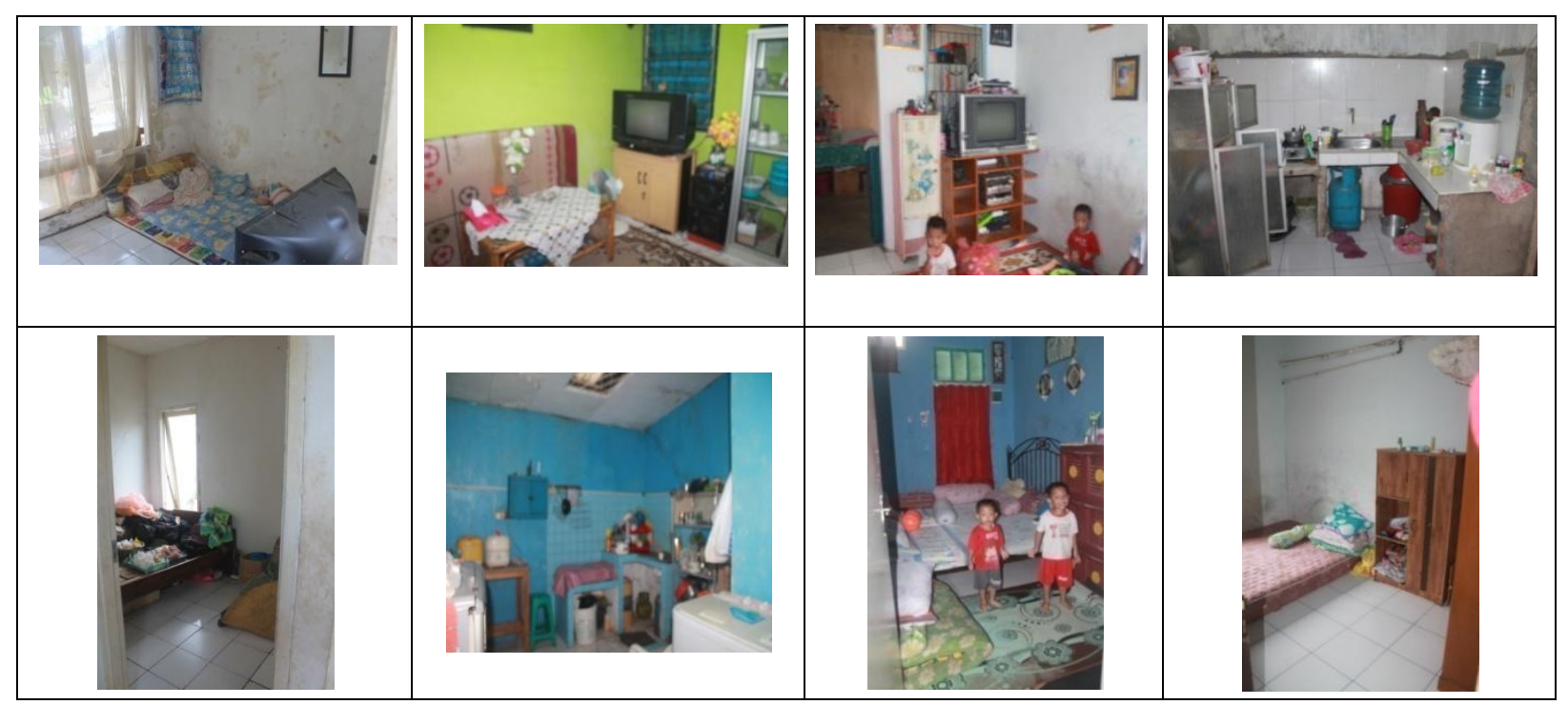

Gambar 1. Pencahayaan dan Bukaan pada RSS di Bekasi Sumber: Observasi Lapangan, 2015

Nurwulandari [4] menyatakan bahwa lubang cahaya ideal adalah $20 \%$ dari luas ruang. Menurut Pedoman Umum Rumah Sederhana Sehat, lubang cahaya minimum adalah persepuluh (1/10) dari luas lantai ruangan [1]. Sedangkan lubang penghawaan minimal $5 \%$ dari luas lantai.
Pencahayaan dan penghawaan berkaitan sangat erat. Hal ini terjadi karena bukaan yang digunakan untuk memasukkan cahaya biasanya juga difungsikan untuk memasukkan udara. 


\section{Penataan Perabot Sebagai Indikator Rumah Sederhana Yang Ergonomis}

Perabot atau furnitur merupakan hal yang penting dalam rumah sederhana sehat. Pemilihan perabot dan perletakannya yang tepat akan membuat ruang gerak yang cukup sehingga membuat pengguna merasa nyaman. Begitu pula sebaliknya pemilihan dan penataan perabot yang salah akan berpengaruh pada kenyamanan dalam ruang. Tabel di bawah akan memperlihatkan hasil analisa luas ruang yang digunakan untuk perabot dan ruang gerak yang dihasilkannya.

Prosentase ruang yang terpakai untuk perletakan perabot pada RSS di Kota Bekasi berkisar antara 3,33\%-45,56\% dari luas ruang. Artinya, luas ruang yang digunakan untuk meletakkan perabot berkisar pada angka tersebut. Prosentase ruang gerak efektif dalam ruang pada RSS di Kota Bekasi berkisar antara $54,44 \%-96,67 \%$ dari luas ruang. Ratarata ruang gerak pada RSS di Kota Bekasi adalah 82,95\%. (selengkapnya di Tabel 5)

\section{Kenyamanan Kualitatif Pada Rumah Sederhana Yang Ergonomis}

Tahap analisa yang terakhir adalah tabulasi dengan mendialogkan temuan di lapangan. Dari dialog tema-tema temuan tersebut akan didapatkan kesimpulan tentang desain RSS yang ergonomis di Bekasi. Data yang sudah dianalisa kemudian didialogkan dengan kenyamanan hasil wawancara.

Tabel 5. Prosentase perabot dan Ruang gerak Efektif pada RSS di Bekasi

\begin{tabular}{|c|c|c|c|c|c|c|c|c|c|c|c|c|c|}
\hline & \multicolumn{3}{|c|}{ K1 } & \multicolumn{3}{|c|}{ K2 } & \multicolumn{3}{|c|}{ K3 } & \multicolumn{3}{|c|}{ K4 } & \multirow[b]{2}{*}{ 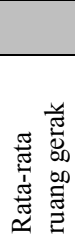 } \\
\hline \multirow{2}{*}{ ruang tamu } & 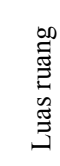 & 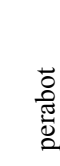 & 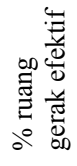 & 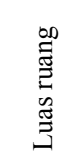 & 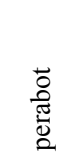 & 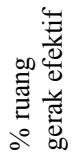 & 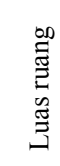 & 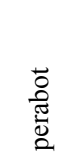 & 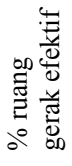 & 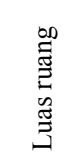 & 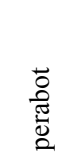 & 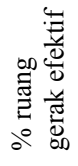 & \\
\hline & 13,5 & 3,1 & 77,04 & 12 & 1,77 & 85,25 & 9 & 0,78 & 91,33 & 9 & 0,56 & 93,78 & 86,85 \\
\hline \multirow{2}{*}{$\begin{array}{l}\text { kamar } 1 \\
\text { kamar } 2\end{array}$} & 9 & 2,92 & 67,56 & 7,5 & 2,72 & 63,73 & 9 & 2,69 & 70,11 & 9 & 2,72 & 69,78 & 67,79 \\
\hline & & & & 9 & 4,1 & 54,44 & & & & & & & 54,44 \\
\hline \multirow{3}{*}{$\begin{array}{l}\text { Dapur } \\
\text { kamar mandi } \\
\text { ruang } \\
\text { serbaguna }\end{array}$} & 9 & 1,14 & 87,33 & 9 & 0,88 & 90,22 & & & & \multirow{2}{*}{$\begin{array}{l}16,5 \\
2,25\end{array}$} & 0,55 & 96,67 & 91,41 \\
\hline & 2,25 & & & 2,25 & & & 2,25 & & & & & & \\
\hline & & & & & & & & & & 21 & 0,78 & 96,29 & 96,29 \\
\hline & 36 & 7,16 & 80,11 & 39,8 & 9,47 & 76,18 & 21 & 3,47 & 83,48 & 57,8 & 4,61 & 92,02 & 82,95 \\
\hline
\end{tabular}

Tabel 6. Kenyamanan kualitatif berdasarkan pencahayaan

\begin{tabular}{|l|l|l|l|l|}
\hline Ruang & K1 & K2 & K3 & K4 \\
\hline Ruang Tamu & nyaman & nyaman & nyaman & Nyaman \\
\hline Kamar tidur 1 & nyaman & nyaman & nyaman & Nyaman \\
\hline Kamar tidur 2 & nyaman & nyaman & & \\
\hline Dapur & nyaman & nyaman & & Nyaman \\
\hline Kamar Mandi & Kurang nyaman & Kurang nyaman & Kurang nyaman & Kurang nyaman \\
\hline Ruang serbaguna & & & & Kurang nyaman \\
\hline
\end{tabular}

Tabel 7. Kenyamanan kualitatif berdasarkan penataan perabot

\begin{tabular}{|l|l|l|l|l|}
\hline Ruang & K1 & K2 & K3 & K4 \\
\hline Ruang Tamu & nyaman & nyaman & nyaman & Nyaman \\
\hline Kamar tidur 1 & nyaman & nyaman & nyaman & Nyaman \\
\hline Kamar tidur 2 & nyaman & nyaman & & \\
\hline Dapur & nyaman & nyaman & & Nyaman \\
\hline Kamar Mandi & nyaman & nyaman & nyaman & Nyaman \\
\hline Ruang serbaguna & & & & Nnyaman \\
\hline
\end{tabular}


Tabel 8. Tabulasi Kenyamanan Kualitatif Berdasarkan Jangkauan Cahaya Dan Prosentase Bukaan Pada Rumah Sederhana Sehat Di Bekasi

\begin{tabular}{|c|c|c|c|c|c|c|}
\hline \multirow[t]{2}{*}{ Nama Ruang } & \multirow{2}{*}{$\begin{array}{l}\text { Rata-rata } \\
\text { luas ruang } \\
\text { (m) }\end{array}$} & \multicolumn{3}{|c|}{$\begin{array}{l}\text { prosentase cahaya pagi } \\
\text { ke seluruh ruangan }\end{array}$} & \multirow{2}{*}{$\begin{array}{l}\text { rata-rata } \\
\text { bukaan }\end{array}$} & \multirow{2}{*}{$\begin{array}{l}\text { Kenyamanan } \\
\text { kualitatif }\end{array}$} \\
\hline & & pagi & siang & sore & & \\
\hline Ruang Tamu & 10,875 & $100 \%$ & $100 \%$ & $100 \%$ & 19,14 & $100 \%$ nyaman \\
\hline Kamar 1 & 8,625 & $100 \%$ & $100 \%$ & $100 \%$ & 17,89 & $100 \%$ nyaman \\
\hline Kamar 2 & 9 & $100 \%$ & $100 \%$ & $100 \%$ & 20,00 & $100 \%$ nyaman \\
\hline Dapur & 11,5 & $67 \%$ & $67 \%$ & $67 \%$ & 21,98 & $100 \%$ nyaman \\
\hline Kamar Mandi & 2,25 & $0 \%$ & $0 \%$ & $0 \%$ & & $100 \%$ kurang nyaman \\
\hline Ruang serbaguna & 21 & $0 \%$ & $0 \%$ & $0 \%$ & 4,57 & $100 \%$ kurang nyaman \\
\hline
\end{tabular}

Dapat disimpulkan bahwa untuk ruang tamu pada RSS di Bekasi rata-rata mempunyai luasan ruang $10,875 \mathrm{~m}^{2}$. Sedangkan ukuran yang umum digunakan adalah $3 \times 3$ meter. Dari 4 kasus rumah yang diteliti, $100 \%$ ruang tamu mendapatkan cahaya merata ke seluruh ruangan pada pagi, siang dan sore hari dengan rata-rata bukaan $19,14 \%$ dari luas ruang. Dengan kondisi seperti tersebut, pengguna rumah merasa ruang tamunya sudah nyaman. Ada $100 \%$ responden yang menyatakan bahwa dengan ukuran ruang dan bukaan tersebut rumah terasa nyaman.

Menurut Nurwulandari tak perlu berlebihan dalam jumlah, ukuran dan bentuk bukaan, semua harus disesuaikan dengan kebutuhan. Menurut data SNI, banyaknya lubang cahaya ideal dalam suatu ruang dinyatakan oleh nilai WWR (Wall Window Ratio [4]). Dari ketentuan ini nilai idealnya adalah $20 \%$ dari luas dinding keseluruhan. Apabila dilihat dari tabel diatas, hanya kamar mandi yang perlu menjadi perhatian. Semua responden mengatakan kamar mandi kurang nyaman, salah satu indikatornya adalah karena kurangnya bukaan untuk memasukkan cahaya dan udara, sehingga kamar mandi terasa lembab dan bau.

Kenyamanan ruang gerak manusia di dalam rumah sangat dipengaruhi oleh penataan (tata letak) perabot dalam ruang yang digunakan untuk beraktivitas sehari-hari. Identifikasi aktivitas dan kebutuhan penghuni merupakan hal terpenting dalam mendisain ruang dalam. Sedangkan desain ruang dan rumah yang memperhatikan aspek ergonomi merupakan konsep yang perlu dimaksimalkan aplikasinya karena berhubungan dengan kebutuhan dan aktivitas manusia sebagai pelaku kegiatan. Dalam naskah publikasinya di E-Journal Graduate UNPAR Vol 1 No 2, Giwan Hardwika Putra menyatakan bahwa tujuan dari analisis ergonomi adalah untuk menyesuaikan suasana kerja dengan aktivitas manusianya agar tercapai kenyamanan secara fungsional sesuai dengan kebutuhannya. Ergonomi menjadi salah satu sarana untuk membuat nyaman penghuni terhadap lingkungan ruangnya. [9]

Tabel 9. Tabulasi Kenyamanan Kualitatif Berdasarkan Ruang Gerak Efektif Pada Rumah Sederhana Sehat Di Bekasi

\begin{tabular}{|l|c|c|c|l|}
\hline Nama Ruang & $\begin{array}{c}\text { Rata-rata } \\
\text { luas ruang }\left(\mathrm{m}^{2}\right)\end{array}$ & $\begin{array}{c}\text { prosentase Ruang } \\
\text { gerak efektif }\end{array}$ & $\begin{array}{c}\text { rata-rata } \\
\text { bukaan }\end{array}$ & $\begin{array}{c}\text { Kenyamanan } \\
\text { kualitatif }\end{array}$ \\
\hline Ruang Tamu & 10,875 & 86,85 & 19,14 & $100 \%$ nyaman \\
\hline Kamar 1 & 8,625 & 67,79 & 17,89 & $100 \%$ nyaman \\
\hline Kamar 2 & 9 & 54,44 & 20,00 & $100 \%$ nyaman \\
\hline Dapur & 11,5 & 91,41 & 21,98 & $100 \%$ nyaman \\
\hline Kamar Mandi & 2,25 & & & $100 \%$ nyaman \\
\hline Ruang serbaguna & 21 & 96,29 & 4,57 & $100 \%$ nyaman \\
\hline
\end{tabular}


Ruang gerak terkait tidak hanya dengan perabot dan penataannya saja melainkan juga dengan bukaan. Bukaan yang dimaksud disini adalah ukuran dan letak bukaannya. Karena setiap ada bukaan baik itu berupa pintu atau jendela, pasti ada ruang gerak. Begitupun dengan setiap penataan perabot pasti akan membutuhkan ruang gerak.

Pada rumah sederhana, kamar biasanya digunakan tidak hanya untuk tidur tetapi juga untuk menyimpan pakaian dan barang-barang pribadi lainnya. Untuk kamar mandi, biasanya pengguna merasa kurang nyaman ketika ada kegiatan lain yang dilakukan bersamaan di kamar mandi misalnya mencuci baju, mencuci piring atau meletakkan pakaian kotor.

\section{KESIMPULAN}

Berdasarkan penelitian tentang pencahayaan dan ruang gerak efektif sebagai indikator kenyamanan RSS yang ergonomis di Bekasi, ada beberapa kesimpulan yang didapatkan

1. Pencahayaan pada rumah tinggal mempengaruhi dua aspek yaitu aspek fisik dan aspek psikologis pada ruang. Peran pencahayaan sangat penting untuk mewujudkan kenyamanan pada rumah sederhana yang ergonomis. Pencahayaan tersebut meliputi jangkauan cahaya, arah bukaan dan elemen yang digunakan untuk memasukkan cahaya.

2. Pada rumah sederhana sehat yang ergonomis, cahaya alami diupayakan bisa masuk ke dalam semua ruang sehingga bisa digunakan untuk beraktivitas tanpa bantuan pencahayaan buatan. Kekurangannya adalah pada kamar mandi, cahaya matahari tidak cukup menjangkau seluruh ruang. Hal ini menjadikan kamar mandi tidak nyaman digunakan.

3. Ukuran bukaan yang terdapat pada rumah sederhana yang diteliti mempunyai ukuran sesuai dengan standar sehingga matahari dapat masuk untuk menerangi ruangan.

4. Penataan perabot menjadi indikator kedua untuk mengukur kenyamanan secara kualitatif. Dari pengukuran didapatkan bahwa ruang gerak efektif (tanpa perabot) pada RSS di Bekasi masih cukup untuk beraktivitas. Hal ini sesuai dengan hasil kenyamanan kualitatif dari penghuni yang menyatakan semua ruang dalam rumahnya nyaman untuk digunakan

\section{UCAPAN TERIMAKASIH}

Penelitian ini dilakukan dengan sumber dana yang dibiayai oleh Kopertis Wilayah III dengan surat Kementerian Pendidikan dan Kebudayaan Tahun Anggaran 2015 nomor 0094/E5.1/PE/2015 Tanggal 16 Januari 2015

\section{REFERENSI}

[1] Anonim. Pedoman Umum Rumah Sederhana Sehat. http://www.pu.go.id/satminkal/itjen/lama/h ukum/km403-0211.pdf. (diakses 20 April 2013)

[2] Manurung, Parmonangan. (2012). Pencahayaan Alami dalam Arsitektur. Yogyakarta : Penerbit Andi.

[3] Iridiastadi, Hardianto dan Yassierli. (2014). Ergonomi suatu Pengantar. Bandung . PT Penerbit Remaja Rosdakarya.

[4] Nurwulandari. (2003). Rumah Hemat Energi. Serial Rumah. Gramedia

[5] Frick, Heinz dan FX Bambang Suskiyatno. (2007). Dasar-dasar Arsitektur Ekologis. Yogyakarta : Penerbit Kanisius.

[6http://www.depkes.go.id/downloads (Ergonomi.PDF)

[7] Purwantiasning, Ari Widyati. (2009). Modul Mata Kuliah Interior I

[8] Moleong, Lexy. Metode Penelitian Kualitatif. Bandung. Remaja Rosdakarya

[9] Putra, Gunawan Hardika. (2014). Efektivitas Ruang dalam Rumah Tipe 36 Ditinjau dari Perletakan Perabot terhadap Ruang Gerak Penghuni. E Journal Graduate UNPAR Vo; 1 No 2. 
